\title{
Improved accuracy of cross borehole radar velocity models for ice property analysis
}

\author{
Charlotte Axtell ${ }^{1}$, Tavi Murray ${ }^{1}$, Bernd Kulessa ${ }^{1}$, Roger A. Clark ${ }^{2}$ and Alessio \\ Gusmeroli $^{3}$ \\ ${ }^{1}$ Glaciology Group, College of Science, Swansea University, \\ Singleton Park, Swansea, SA2 8PP, UK \\ 2 Institute of Geophysics and Tectonics, School of Earth and Environment, \\ University of Leeds, Leeds, LS2 9JT, UK \\ ${ }^{3}$ International Arctic Research Center, University of Alaska \\ Fairbanks, Fairbanks, AK, USA
}

(September 24, 2015)

Second Revision

Running head: Errors in glacier cross borehole radar

\begin{abstract}
Cross-borehole radar (XBHR) is widely used for the quantification of pore-scale liquid water in geological materials, inferred from bulk velocity variations caused by differences in electromagnetic properties between the water and the surrounding material. XBHR can accurately and repeatedly measure variation at depth, with sampled material remaining under natural stresses, whilst maintaining good lateral sampling. However, even small errors in measured radar velocities result in large errors in water-content estimates, emphasising the need to both quantify and minimize errors. Here, we rigorously assess the sources of uncertainty in XBHR surveys undertaken in a glaciological setting. We summarise and quantify the
\end{abstract}


three main areas of uncertainty in data collection: [1] instrument time-drift, [2] first-break picking, and [3] borehole geometry. Our analysis of field data shows that contemporary acquisition procedures can produce velocity errors of $\pm 3.0 \%( \pm 0.0050 \mathrm{~m} / \mathrm{ns})$, equivalent to \pm 0.84 volumetric $\%$ water-content. We propose several revisions to produce improved data acquisition. Through enhancement of existing techniques, the velocity uncertainties are improved to $\pm 1.5 \%$. We also propose the measurement of borehole diameter when hotwater drilling, which can hypothetically further reduce the velocity uncertainty to $\pm 0.8 \%$, equivalent to \pm 0.2 volumetric $\%$ water-content. The need for such precise measurement is clear because an increase in englacial water-content, from 0 to $0.8 \%$, has been proven to triple the strain rate and soften the ice. Liquid water between ice crystals has also been linked to faster velocities in ice streams, and surging events. 


\section{INTRODUCTION}

Measurement of pore-scale water is important in geological settings; in glaciological environments, water is observed within bubbles, or in veins between grains (Mader, 1992) equivalent to pore-space in rocks (Endres and Knight, 1991). An increase in ice watercontent from $0 \%$ to only $0.8 \%$ will decrease ice viscosity (Lliboutry, 1976) and triple the strain rate (Duval, 1977).

Englacial liquid water-content varies greatly, both laterally (Pettersson et al., 2004) and vertically (Murray et al., 2000a) with typical values between 0.5 and 1.5 volumetric \% water (Zryd, 1991), with some measurements up to $4 \%$ in ice (Macheret and Glazovsky, 2000; Moore et al., 1999) and 9\% in firn (Arcone, 2002). Direct, thermodynamic methods measure the speed of propagation of a freezing front, which is directly related to the water-content and are considered highly sensitive to the quantity of liquid water in an ice volume (Hutter et al., 1990). However, thermodynamic methods commonly require ice core removal from the natural stress regime, are non-repeatable, and limit measurements to the sample point (Duval, 1977; Vallon et al., 1976; Zryd, 1991). Geophysical methods sample representative in-situ ice volumes, quantifying liquid-water variation through relative changes in electromagnetic velocity. Surface acquisition provides spatially extensive data, but the presence of water causes signal loss (attenuation), reducing accuracy at depth, and requiring knowledge of the near-surface properties (Pettersson et al., 2004). The choice between thermodynamic and surface geophysical methods requires a compromise between accuracy and spatial sampling.

Cross borehole radar is widely used for the determination of liquid water-content in many geological materials, calculated from the velocity variations caused by the extreme differ- 
ences in electromagnetic properties between water and the surrounding material (Alumbaugh et al., 2002; Binley et al., 2002); tiny changes in water-content $(\sim 0.4 \%)$ are represented by equally minute variations in radar velocity for glacier ice $( \pm 0.003 \mathrm{~m} / \mathrm{ns}$, Gusmeroli et al., 2010). Removing the need for knowledge of near-surface properties, borehole surveys significantly improve the accuracy of measurements at depth relative to surface surveys (Murray et al., 2007). Sampling can be completed over large depth ranges, at multiple locations, with several survey orientations at each site (Hubbard and Nienow, 1997; Gusmeroli, 2010); use of each borehole is typically possible in temperate glaciers up to several days after drilling (Jansson and Näslund, 2009).

Cross borehole radar surveys use transmitter and receiver antennae placed within adjacent boreholes, and can be acquired as zero-offset profiles, or multi-offset gathers (Annan, 2005). The radiated electromagnetic energy propagates directly through the subsurface at a speed determined by the material properties between the two boreholes, e.g. dielectric permittivity $(\varepsilon)$ - a measure of a material's ability to store charge and inhibit current flow (Turner and Siggins, 1994). For a zero-offset profile, the antennae are positioned at equal depths, and moved a fixed depth-increment $(\Delta z)$ between measurements. This is a quick and simple survey method used to observe a 1D velocity variation with high spatial resolution and large sampling volume (Huisman et al., 2003; Gusmeroli et al., 2010). For multi-offset gathers, one antenna location remains fixed and data are recorded while the other is moved within the adjacent borehole; the fixed depth antenna is then moved by $\Delta z$ and the process repeated. Multi-offset gathers sample the same material volume from a range of orientations, delivering a $2 \mathrm{D}$ heterogeneous property map of the volume between the boreholes (Binley et al., 2002). Data collection is time consuming (Annan, 2005), and interpretation of subsurface velocities requires the use of inversion algorithms (Peterson, 
2001; Oberröhrmann et al., 2013). This study focuses on zero-offset profiles, for their potential for greater spatial sampling, while maintaining vertical precision (Murray et al., 2007). However, the relationship between these different acquisitions means the following discussion is still highly applicable to data from multi-offset gathers (Oberröhrmann et al., 2013).

This paper aims to evaluate the uncertainties affecting velocities measured from crossborehole radar surveys, during data collection and processing. We quantify the velocity model uncertainties and assess the impact they have on the water-content estimation. We evaluate the uncertainties in field data acquired with "standard" data collection, and the implication this has on property analysis. We find the velocity errors are far smaller than those calculated for surface data (Barrett et al., 2007; Murray et al., 2007). This study is motivated by a specific glaciological application, where the uncertainties have a relatively greater influence due to the large difference in dielectric properties, but its principles are generic, and applicable to other subsurface settings (although in them, the magnitude of implied uncertainties may differ).

The presence of temperate ice (containing water inclusions) has been associated with fast ice velocities at the base and shear margins of ice streams (Lüthi et al., 2002; Schoof, 2012) and during glacial surging (Murray et al., 2000b; Cohen, 2000). Quantifying englacial watercontent is key to understanding the rheological properties of temperate ice, and improve any predictions of ice flow rate. The current collection procedure is not sufficient to accurately determine the water-content for rheological analysis. We suggest improvements to data acquisition and processing that reduce uncertainties enough to calculate ice properties with a usable accuracy and precision. 


\section{THEORETICAL VELOCITY ANALYSIS}

Improving the accuracy of the water-content calculation first requires consideration of the data collection procedure, to help minimise uncertainties on the velocity-model. A theoretical survey is summarised, quantifying the uncertainty at each step. We also assess the impact these errors have on estimates of microscale water-content.

\section{Cross borehole radar}

Cross borehole radar data are collected in down-hole (antennae moved from the surface to the base of the borehole) or up-hole (base to surface) directions. This records the time, $\mathrm{t}_{a}$ (Figure 1a), for the electromagnetic energy to propagate between two boreholes. Additional measurements of the borehole inclination (deviation from vertical), and differential dGPS locations of the borehole positions on the ice surface are used to interpret their separation. The main controls on borehole geometry when drilling with hot water are drill speed, water temperature, and driller experience, hence the borehole geometry (inclination, diameter) can vary significantly from surface to base. A magnetic inclinometer tool is used to measure borehole dip and dip-azimuth, calculating deviation from vertical; when combined with dGPS measurements of borehole surface locations, we can calculate borehole separation (S), and changes therein with depth.

The radar data acquisition includes collection of the main borehole data (Figure 1a), as well as calibration data, acquired prior to and after the main survey with antennae placed at predefined offsets $\left(X_{i}\right)$ on the ice surface (Oberröhrmann et al., 2013). Additional calibration data can be collected during data acquisition for longer total survey times, e.g. every 10 traces during a multi-offset gather (Binley et al., 2002; Oberröhrmann et al., 2013). 
Calibration trace arrival times at all offsets should be equal before $\left(T_{S 1}\right)$ and after $\left(T_{S 2}\right)$ the survey (Binley et al., 2002; Alumbaugh et al., 2002). If $T_{S 1} \neq T_{S 2}$, a time drift $\left(T_{D}\right)$ has occurred (Gusmeroli, 2010); Sensors \& Software Inc. (2006) suggest this may occur due to dirty optical cables. Some studies apply a linear drift-correction in an attempt to remove the effect, removing 0 ns from the first trace, and the total drift $\left(\mathrm{T}_{D}\right)$ on the final trace (A.Binley, personal communication, 17/11/2014). The velocity of electromagnetic waves in air $\left(v_{A}\right)$ is known $(0.3 \mathrm{~m} / \mathrm{ns})$, therefore we can calculate the appropriate time shift to start the data record at the zero-offset time ( $t_{0}$; Gusmeroli, 2010) - a process known as the Time-Zero Correction:

$$
t_{0}=\frac{v_{A}}{X_{i}}-\frac{T_{S 1}+T_{S 2}}{2}
$$

The time-zero correction allows the correct interpretation of energy travel times $\left(t_{a}\right)$ within the main data; when combined with the calculated borehole separation, the velocity at each depth within the borehole can be inferred.

\section{Uncertainties}

Each stage of data collection and processing incurs uncertainty, affecting the calculated velocity model, which we can separate into spatial and temporal errors. Here we summarise and quantify the significant uncertainties on cross-borehole radar velocity models, to determine the accuracy in our results, and to attempt to mitigate their effects. 
First-break picking

Radar data are considered minimum-phase, where the amplitude is 0 at the onset of energy, followed by a rapid increase (the first-break) to an absolute maximum amplitude at the first peak (Schoenberger, 1974). Picking the first-break $\left(\mathrm{T}_{F B}\right)$ is standard practice to measure energy arrival times. In noise-free data, this is relatively easy; in low amplitude, high noise data, or where multiple arrivals interfere, the first-break may not be clear (Figure 2).

The absolute maximum amplitudes (peaks and troughs in the data) are more consistent and theoretically easier to pick; they can be used to calculate the first-break by removing the appropriate portion of the wave period $\left(\lambda_{t}\right)$ :

$$
T_{F B}=T_{P}-\frac{2 n-1}{4} \lambda_{t}
$$

where $T_{P}$ is the arrival time of $n$th "peak" of energy. It is also unlikely digital sample times

$(d t)$ coincide precisely with the energy arrival, adding an additional uncertainty of $\frac{1}{2} d t$ to temporal error assessment. The consistency between picking first-break (FB) or calculating first-peak (FP) arrival times can be used to assess data reliability, as does the measurement of up- and down-hole data. Zero-offset travel time picks have also been used to validate arrival times calculated in equivalent multi-offset gather data (Oberröhrmann et al., 2013), which further emphasises the necessity for accuracy.

\section{Instrument drift}

We found that time-drift occurs randomly, both gradationally (across many traces) and instantaneously (within a single trace), in both positive and negative time-jumps. The 
effect of time-drift on the velocity model is difficult to quantify reliably, particularly for an inadequately defined time-drift distribution. Therefore, we assume maximum error, where the total drift is applied instantaneously in the first trace affecting the entire model. We initially create a set of synthetic travel times for a range of borehole separations and ice radar velocities. We add an instantaneous time-drift (in ns) to the synthetic travel times and calculate new, drift-influenced velocity models. The difference between the initial, synthetic velocities, and the drift-influenced velocity models are calculated using a root-mean square deviation for a range of time-drifts.

Unsurprisingly, large time drifts and/or small borehole separations (S) result in the greatest uncertainty, e.g. $\mathrm{T}_{D}=2 \mathrm{~ns}$ produces uncertainties of $\pm 0.0027 \mathrm{~m} / \mathrm{ns}$ and \pm 0.0014 $\mathrm{m} / \mathrm{ns}$, at $\mathrm{S}=20$ and $40 \mathrm{~m}$, respectively. This uncertainty is reduced by $\sim 40 \%$ by applying the linear drift-correction (removing $0 \mathrm{~ns}$ from the first trace, and the total drift $\left(\mathrm{T}_{D}\right)$ on the final trace). The difference between cold (water-free) and temperate ice can be as little as $\pm 0.003 \mathrm{~m} / \mathrm{ns}$ (Gusmeroli et al., 2010), hence we apply an error limit of $\pm 0.002 \mathrm{~m} / \mathrm{ns}$. For example, where $\mathrm{S}=20 \mathrm{~m}, \mathrm{~T}_{D}>1.5 \mathrm{~ns}$ results in uncertainty $>0.002 \mathrm{~m} / \mathrm{ns}$ - hence surveys where $\mathrm{T}_{D}>1.5$ ns are considered unreliable.

Misplaced surface antennae can cause apparent time drift where $\mathrm{T}_{S 1} \neq \mathrm{T}_{S 2}$. The York et al. (2004) regression method can be applied to travel times for multiple offsets, calculating a linear fit between points with errors (in time and space), and a more accurate $t_{0}$. Small offsets ( $<$ borehole separation), where antennae are positioned with a tape measure have larger associated errors $(d X)$ due to human error. Where offset is equal to borehole separation, antennae positioning is effectively recorded by dGPS and highly accurate. Where surface data collected at a single offset is used to calculate $t_{0}$, the error $\left(d_{t_{0}}\right)$ is calculated using: 


$$
d_{t_{0}}=\frac{d X}{v_{A}}+\frac{1}{2} d t
$$

where $v_{A}$ is the electromagnetic velocity in air.

Time-drift can have a substantial influence on the output velocity model, as it influences both the time-zero correction and the main data picks. It is necessary to collect multi-offset surface data, with at least one large offset ( $\geq$ borehole separation) to ensure accurate determination of $\mathrm{T}_{D}$ and $t_{0}$, and prevent unnecessary rejection of good data.

\section{Borehole geometry: diameter}

The significantly lower electromagnetic velocity in water, and the inability of radar to distinguish between micro- and macro-scale water bodies (e.g. veins between crystals, and crevasses, respectively) mean the in-borehole energy travel must be calculated to avoid underestimating the ice velocity. Borehole diameter measurements are currently not a standard acquisition procedure and there is no indication of how diameter miscalculations affect the velocity model.

When hot-water drilling, borehole diameter is mainly controlled by water circulation. During processing, boreholes are generally assumed tubular with a constant diameter. Water circulation from steam drilling causes a $1 \mathrm{~cm}$ diameter variation over $30 \mathrm{~m}$ depth (Heucke, 1999). Schwerzmann et al. (2006) measured borehole diameter with an 8-arm calliper tool after fixed-width drilling, observing increased borehole diameter and eccentricity in the top $5-15 \mathrm{~m}$, relative to the rest of the borehole. We argue diameter variation from hot-water drilling is even larger.

The total travel time of electromagnetic energy is accumulated from propagation through 
each medium along the path length; the travel time within the borehole is simplified to $\frac{1}{2} D_{W} / v_{W}$, where $D_{W}$ is the cross-hole diameter of the borehole (Figure 1). Similarly, the travel time within ice is $\left(S-D_{W}\right) / v_{I}$, assuming the borehole diameters are equal. The total travel time can then be calculated:

$$
T_{\text {total }}=\frac{D_{W}}{v_{W}}+\frac{S-D_{W}}{v_{I}}
$$

Again, synthetic travel times are calculated for a range of borehole separations and input ice velocities, and a borehole diameter decreasing with depth at the rate measured by Heucke (1999) - a minimum error when hot-water drilling. The root-mean squared deviation is calculated between the synthetic-velocities and those calculated for a range of assumed borehole diameters. Unsurprisingly, the uncertainty is greatest for large diameter errors, and/or smaller borehole separations, e.g. $\pm 3 \mathrm{~cm}(20 \%)$ diameter error, produces uncertainties of $\pm 0.0011 \mathrm{~m} / \mathrm{ns}$ and $\pm 0.0005 \mathrm{~m} / \mathrm{ns}$, at $\mathrm{S}=20$ and $40 \mathrm{~m}$, respectively.

These errors will likely be larger when hot-water drilling, especially for inexperienced drillers. The diameter can be measured synchronously with the inclinometer survey, maintaining the tool position in the borehole centre, as shown by Schwerzmann et al. (2006). This measurement significantly reduces the diameter uncertainty, hence the effect on the velocity model is considered negligible.

\section{Borehole geometry: inclination}

Standard velocity calculations assume a straight, horizontal path between two vertical tubu-

lar boreholes, with centrally positioned antennae. Borehole inclination is measured to in- 
terpret variation in antenna separation and avoid large spatial errors. The difference in dielectric properties of ice and water implies a small critical angle $\left(\theta_{c}=\sin ^{-1}\left(v_{I} / v_{W}\right)\right)$ where the energy is refracted along the ice-water interface rather than transmitted in the second medium. Assuming radial energy dispersion from the antenna, there are only a small range of angles within the borehole where energy is transmitted, affected by the internal wall angle and cross-sectional eccentricity. The antenna will probably rest obliquely to the borehole axis when the latter is not vertical (Figure 1b; Schwerzmann et al., 2006). Vertical-depth and borehole-depth will also be non-equal for inclined boreholes, resulting in an angled energy travel path (Figure 2). The borehole antenna can be approximated by a vertical dipole, with the strongest energy radiated horizontally from the antenna (Tronicke and Knoll, 2005); this can result in signal loss where the direct energy path is non-parallel to the surface.

The true energy path will likely be near-perpendicular to the internal borehole edge, which can incur additional path length within water and ice. The effect is largest in-line with borehole dip-azimuth, and weakest perpendicular to this. For example, a dip of $45^{\circ}$ (observed in real data) means an extra $4 \mathrm{~cm}$ is travelled in ice, and $0.3 \mathrm{~cm}$ in water, assuming $b / a$ is 1 , where $a$ and $b$ are the long and short axes of an ellipse, respectively. Refraction of energy can also reduce recorded signal strength.

Correcting for the energy refraction requires precise knowledge of the internal borehole shape, resulting in insignificant improvement of the uncertainties. Realistically, borehole walls undulate as heterogeneous ice properties result in different melting speeds; we consider this equivalent to miscalculating the spatial positioning, and incorporate it into the borehole separation error $\left(d_{S}\right)$ : 


$$
d_{S}=\left[d_{N}^{2}+d_{E}^{2}+d_{I 1}^{2}+d_{I 2}^{2}\right]^{1 / 2}
$$

(Topping and Worrell, 1957), where $d_{N}$ and $d_{E}$ are Northing and Easting dGPS location errors $( \pm 5 \mathrm{~cm})$, and $d_{I 1}$ and $d_{I 2}$ are inclination uncertainties calculated for each borehole relative to the other. Magnetic inclinometers are accurate to $\pm 0.1^{\circ}$, but it is important to use a centralizer to accurately measure true borehole deviation.

\section{Revised data acquisition}

Standard data collection involves measurement of the borehole inclination and surface locations, in addition to the radar data, which includes borehole and surface calibration data. Herein, we propose acquiring surface calibration data at multiple offsets, which will improve accuracy in the time-zero correction and drift calculation. Data acquisition should be repeated, e.g. up- and down-hole, while avoiding data clipping, ensuring precision in the calculated first-break times. We also propose measuring borehole diameters during the data collection synchronously with inclinometer data (Schwerzmann et al., 2006), to account for diameter variations caused by water circulation and heterogeneous ice properties.

\section{Water-content estimation}

Interpreting changes in the subsurface properties (e.g. water-content) from changes in measured bulk velocity requires various assumptions about the pore-structure geometry, and/or dielectric properties of the constituent parts. The majority of effective medium models consider variations in the dielectric permittivity $(\varepsilon)$, which is inversely proportional to the radar velocity, $v=c / \sqrt{\varepsilon}$, where $c$ is the electromagnetic velocity in a vacuum $\left(\approx v_{A}\right)$. For 
example, the Looyenga (1965) model assumes an isotropic arrangement of two phases (Endres et al., 2009), appropriate for large concentrations of spherical air and water inclusions, hence it is used to estimate water-content in snowpack (Heilig et al., 2009). Gusmeroli et al. (2010) expanded two-phase Looyenga formula for ice, accounting for air by removing the $v_{a}$ component from the measured velocities, to calculate a bulk velocity within just ice and water.

We employ the three-phase Complex Refractive Index formula, which weights the dielectric permittivities $(\varepsilon)$ of the each material by their respective fractional volumes, to calculate the total (bulk) permittivity of a mixture:

$$
\sqrt{\varepsilon_{m}}=\left(1-\phi_{w}-\phi_{a}\right) \sqrt{\varepsilon_{i}}+\phi_{w} \sqrt{\varepsilon_{w}}+\phi_{a} \sqrt{\varepsilon_{a}}
$$

(Greaves et al., 1996). With prior knowledge of the fractional air-content, Equation 6 can be rearranged used to calculate the water-content:

$$
\phi_{w}=\frac{c / v_{m}-\sqrt{\varepsilon_{i}}+\phi_{a}\left(\sqrt{\varepsilon_{i}}-\sqrt{\varepsilon_{a}}\right)}{\sqrt{\varepsilon_{w}}-\sqrt{\varepsilon_{i}}} .
$$

The inferred values of $\phi_{w}$ are the closest approximation of the arithmetic average of the Hashin-Shtrikman bounds (Mavko et al., 2009), hence produce the best estimate of watercontent without knowledge of the porescale geometry. The radar velocity in ice $\left(v_{i} \approx 0.168\right.$ $\mathrm{m} / \mathrm{ns})$ is significantly faster than in water $\left(v_{w} \approx 0.032 \mathrm{~m} / \mathrm{ns}\right)$, but significantly slower than in air $\left(v_{a}\right)$, thus ignoring or underestimating air-content will underestimate the water-content.

Based on Equation 7, an uncertainty in the measured bulk velocity $\left(v_{m}\right)$ of \pm 0.034 $\mathrm{m} / \mathrm{ns}\left( \pm 2 \%\right.$, where $\left.v_{m}=0.168 \mathrm{~m} / \mathrm{ns}\right)$ results in a $\pm 0.56 \%$ water-content error, assuming 
a known $\phi_{a}$. This error is relatively large for low porosities, being a $93 \%$ error for a $\phi_{w}$ of $0.6 \%$, for example. A $\pm 2 \%$ air-content uncertainty results in a tiny $\pm 0.05 \%$ water-content error. Although we cannot ignore $\phi_{a}$, it does not require a highly precise calculation to significantly improve the overall water-content error.

In addition, the dielectric permittivity of water $\left(\varepsilon_{w}\right)$ is temperature-dependent. Variation of $\varepsilon_{w}$ with temperature $\left(<0^{\circ} \mathrm{C}\right)$ is approximated by Kaatze $(2007)$, calculated by:

$$
\varepsilon_{w}=94.9 \exp \left[-5.63 \times 10^{-3}(T-258.15)\right],
$$

where $\mathrm{T}$ is in Kelvin. Air-content is also temperature- and pressure-dependent, however, sensitivities to these parameters are very small $\left(5 \times 10^{-6} /{ }^{\circ} \mathrm{C}\right.$ and $100 \times 10^{-6} /$ atm; Heidary, 2010), therefore can be assumed negligible.

There are several parameters affecting the dielectric permittivity of ice, including temperature, density, crystal orientation, and impurity content (Fujita et al., 2000). The temperature-dependence of $\varepsilon_{i}$ is estimated by:

$$
\varepsilon_{i}=3.188+9.1 \times 10^{-4} T
$$

(Mätzler and Wegmüller, 1987), where $T$ is temperature in ${ }^{\circ} \mathrm{C}$. Density changes result from increased overburden pressure (Fujita et al., 2000); the most significant variations are caused by air bubbles within the ice - accounted for by using a three-phase model. We estimate the decrease in air-content with depth using a pressure curve (Bradford et al., 2009). Preferred crystal fabrics develop in regions of high-shear (Fujita and Mae, 1993), but only changes ice permittivity $\left(\varepsilon_{i}\right)$ by $\sim 1 \%$ (Johari and Charette, 1975; Fujita and Mae, 1993; Bohleber 
et al., 2012), therefore this effect is assumed negligible. Increased impurity concentration is strongly associated with a linear decrease in $\varepsilon_{i}$, measured by the simple relation:

$$
\varepsilon_{i}=\varepsilon_{I}+\frac{d \varepsilon_{i}}{d C} C
$$

(Fujita et al., 2000), where $C$ is the impurity concentration, $\varepsilon_{I}$ is the dielectric permittivity

of pure ice. At $100 \mathrm{MHz}$ and $\sim 0^{\circ} \mathrm{C}, \frac{d \varepsilon_{i}}{d C}$ is 40 , however, this value is strongly temperatureand frequency-dependent (Fujita et al., 2000; Bohleber et al., 2012). Impurities also affect the ice conductivity, increasing signal attenuation; the influence depends on the impurity type, concentration and location e.g. soluble vs insoluble. These properties will vary based on the location of the study.

\section{RESULTS}

We quantify uncertainties in cross-borehole radar surveys, comparing data acquired using the previously outlined standard field procedure, and through a more detailed data acquisition. We identify the subsequent effect of these uncertainties on the calculated watercontent. We also identify the hypothetical improvement that results from the application of all our revised field practices on both data examples.

\section{Data collection}

The data were collected in summer 2009, in the ablation area of the mountain glacier Stor-

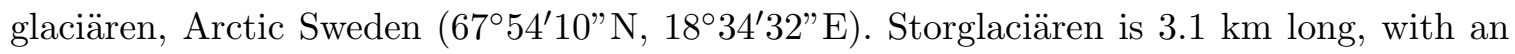
average thickness of $95 \mathrm{~m}$ (Jansson, 1996; Holmlund et al., 2005). The glacier is polythermal, consisting mainly of temperate ice, containing water inclusions, with a 20 - 30 m thick, 
insulating cold-ice surface layer (Gusmeroli et al., 2012). The drill sites are located in the upper (A) and middle (B) ablation area (Figure 3).

The cross-borehole data were collected with 100 MHz MALÅ Geoscience RAMAC GPR Borehole Antennas. Measurements were taken between five borehole pairs at site A, and four at site $\mathrm{B}$, in $1 \mathrm{~m}$ depth-steps to the maximum borehole depth $(46-112 \mathrm{~m})$. The boreholes were drilled using the Stockholm University hot water drill (Jansson and Näslund, 2009), using heated glacial meltwater ejected at pressure through a conical drill tip at the end of a 2 $\mathrm{m}$ long rigid steel drill stem, which helps maintain the vertical borehole. The boreholes were all terminated englacially to prevent drainage and interaction with the subglacial system (Gusmeroli et al., 2010). Site A represents a thorough acquisition, closest to the revised procedure, with surface data collected at multiple offsets, and the borehole data acquired up- and down hole (Figure 4). Site B represents minimal acquisition, where surface data are collected at only one offset, and the borehole data in the down-hole direction only.

Borehole surface locations were measured with a Trimble differential GPS system. Borehole dip $(\gamma)$ and dip-azimuth $\left(\Phi_{d}\right)$ were measured in $2 \mathrm{~m}$ depth steps using a MI-3 Magnetic Inclinometer tool from Icefield Instruments Inc.; these data were collected on a palm device and processed using Inclin (by Icefield Instruments Inc.). The depth of the inclinometer is controlled by the user using a marked cable; the deviation in northing and easting is calculated from the local declination. Incorrect declination creates large inaccuracies for steeply inclined boreholes because they translate to errors in borehole separation and hence the velocity model. 


\section{Storglaciären Velocity models}

We calculate time-drift in the data prior to the velocity model calculation; one profile from

site $\mathrm{A}$, and two profiles from site $\mathrm{B}$ are determined unreliable due to excessive drift (resulting in velocity model uncertainties $>0.002 \mathrm{~m} / \mathrm{ns}$ ). Where data are collected down- and up-hole (A), if the shift is gradational, and occurs in just the down- OR up-hole data, then it can be quantified and removed. Where the drift is instantaneous, creating an anomalous time jump, the correct first-break can be calculated from picking the peaks of the wavelet. If the data were not repeated (up- and down-hole), this change would not be observed, and we would be unable to conclude confidently that the calculated velocity model was accurate. On average, we found that up- and down-hole travel times at site A differed by \pm 1 ns.

The velocity-depth models are calculated for each site using:

$$
v=\frac{\left(S-D_{W}\right)}{T_{t o t}-\frac{D_{W}}{v_{W}}},
$$

where $T_{t o t}$ is the total travel time, calculated by applying the Time-Zero Correction to the first-break time picks. Average velocity models for each field site are represented in Figure 5 by solid (or dashed) lines, and model uncertainties as shaded regions; the values for each site are also shown in Table 1 with one standard deviation $(\tilde{\sigma})$ indicating variation, and the average error at the site $\left(d v_{m}^{-}\right)$.

The velocity model at site A (Figure 5, A) demonstrates a near-constant $(0.169 \mathrm{~m} / \mathrm{ns}$ ) velocity within the top $30 \mathrm{~m}$, followed by a velocity increase to $0.171 \mathrm{~m} / \mathrm{ns}$ at $\sim 60 \mathrm{~m}$ depth, and then a decrease to $0.166 \mathrm{~m} / \mathrm{ns}$ at $\sim 105 \mathrm{~m}$. The average velocity for the site is 0.169 $\pm 0.003 \mathrm{~m} / \mathrm{ns}(1.5 \%)$. The velocity model at site B (Figure $5, \mathrm{~B}$ ) demonstrates an average 
velocity of $0.168 \pm 0.001 \mathrm{~m} / \mathrm{ns}$ in the top $20 \mathrm{~m}$, with a decrease to $0.165 \mathrm{~m} / \mathrm{ns}$ at $\sim 23 \mathrm{~m}$ depth, followed by a $2.4 \%$ velocity decrease down to $84 \mathrm{~m}$. The average velocity for the site is $0.165 \pm 0.005 \mathrm{~m} / \mathrm{ns}(3.0 \%)$; the uncertainties are larger at B than for site A.

\section{Storglaciären Water-Content}

We use the Complex Refractive Index equation (Equation 6) to estimate the ice properties on Storglaciären. Thermistor measurements of the ice indicate a temperature variation between $-5^{\circ} \mathrm{C}$ to $\sim 0^{\circ} \mathrm{C}$ (Gusmeroli et al., 2010), hence we can assume temperature-dependence is negligible for all constituent parts. We approximate conductivity from ice lenses in snowpit data (Ingvander et al., 2013) to be $\sim 25 \mu \mathrm{S} / \mathrm{m}$, which agrees with low frequency measurements made by Walford et al. (1987). We therefore assume the dielectric permittivities of air and water are equal to 1 and 87.9, respectively (Murray et al., 2000b; Endres et al., 2009), and ice to be equal to 3.188, as calculated by Bohleber et al. (2012) for ice using $100 \mathrm{MHz}$ radar. We can also interpret any velocity variation on Storglaciären to be due to changing ice properties.

We estimate the air-content based on the pressure curve from Bradford et al. (2009), assuming an exponential decrease from the surface due to pore-space compression; Gusmeroli et al. (2010) predicted surface air-content between 3 and 4\%. We use an iterative approach to calculate water-content. First, an input air-content ( $\phi_{a}$, pressure curve) is used to infer the water-content $\left(\phi_{w}\right)$. At all points where $\phi_{w}<0$, values are shifted to equal 0 . A new $\phi_{a}$ profile is calculated from the adjusted $\phi_{w}$, and the same approach is applied, assuming $\phi_{a}$ is not less than 0 . This continues until $\phi_{w}, \phi_{a} \geq 0$ is true at all depths. The final $\phi_{a}$ profile is considered more reliable where there is minimal deviation from the original profile; large 
variation implies there are more complicated processes involved.

The average site water-content profiles are outlined in Figure 6a, with the air-content estimations in Figure $6 \mathrm{~b}$. Both $\phi_{w}$ and $\phi_{a}$ are expressed as volumetric fractions. The average water-content for each field site is also outlined in Table 1, with one standard deviation to indicate variation, and the averaged site error $\left(d \Phi_{m}\right)$.

Site A demonstrates negligible water-content; for most of the profile, $\phi_{w} \approx 0$, with anomalous increases at 50, 85, and $105 \mathrm{~m}$. It also demonstrates an air-content profile that significantly differs from the input. Site B produces a water-content with a distinct 2-layer structure: the top $20 \mathrm{~m}$ has a water-content of $0.2 \%$, increasing sharply at $21 \mathrm{~m}$ to $0.5 \%$, and stabilizing at $0.6 \%$ near $40 \mathrm{~m}$ depth. The profile increases again to $0.75 \%$ between 60 and $84 \mathrm{~m}$ depth. The top $5-10 \mathrm{~m}$ of profiles at both sites demonstrate significantly increased water-content. The average water-contents from each site are: $\mathrm{A}=0.06 \pm 0.41 \%$, and $\mathrm{B}=0.51 \pm 1.31 \%$.

\section{DISCUSSION}

We assessed uncertainties in velocity and their effect on the proposed water-content model, finding that a $2 \%$ velocity error results in a \pm 0.56 volumetric $\%$ error in water-content. We evaluated errors in data acquired using minimal (B) and more detailed (A) data collection procedures. The minimal (standard) data acquisition resulted in an average velocity uncertainty of $3.0 \%$, equivalent to \pm 0.84 volumetric $\%$ water-content. The detailed acquisition improved on existing data collection techniques, and decreased the average velocity uncertainty to $1.5 \%$, equivalent to \pm 0.42 volumetric $\%$ water-content. These represent a significantly improved accuracy compared to surface surveys, which produce a best-case 
velocity error of $\sim 8 \%$ (Barrett et al., 2007).

However, in order to calculate water-content variation to $\pm 0.1 \%$, we require a velocity accuracy of $\pm 0.5 \%(<0.001 \mathrm{~m} / \mathrm{ns})$. Uncertainties can be reduced through the application of additional field procedures discussed herein: measuring borehole width, use of multiple surface offsets in calibration data, and surveying both up- and down-hole. For this study we analysed how errors in these data would change if these revisions were made.

Using our methods, we observe that an accuracy of $\pm 0.2 \mathrm{~ns}$ is possible for the timezero correction - calculated from the example in Figure 4, for multiple surface offsets and measuring negligible time-drift - hence we use this as a "best case" scenario. We assume borehole width is measured, and hence the uncertainty in this is negligible, and also assume all data are recorded up- and down-hole. We find the average site errors can be reduced to $\pm 0.0013 \mathrm{~m} / \mathrm{ns}(0.8 \%)$ and $\pm 0.0015 \mathrm{~m} / \mathrm{ns}(0.9 \%)$, for sites A and B, respectively. With these uncertainties we are able to quantify volumetric water-content with much higher precision, to $\pm 0.2 \%$, far exceeding the accuracy we achieve using standard processing routines.

It is also important to consider the interpretation of the polythermal structure from these data. We expect fast surface velocities $(\geq 0.168 \mathrm{~m} / \mathrm{ns})$, followed by a sharp decrease in velocities at the cold-temperate transition surface, because of increased liquid-water, and, finally, a further velocity decrease as pressure build-up increases water-content and decreases air-content. Only site B demonstrates a sharp decrease at $21 \mathrm{~m}$ depth - consistent with the cold-temperate transition surface depth quoted in Gusmeroli et al. (2010). However, this is also the only site where data collection is not repeated up-hole; sharp time-jumps can also result from time-drift, and without the up-hole data, we cannot confidently interpret this as the precise depth of the temperate ice. Both sites also demonstrate an increased 
water-content in the near-surface (top 2-5 m), which we interpret as a transient warm ice layer (Irvine-Fynn et al., 2011) from summer melting. This effect is observed in the velocity model, although less pronounced - the water-content profiles are influenced strongly by the assumed high surface air-content.

The thickness of the surface temperate layer is controlled by air-temperature and varies temporally, much like the cold ice thickness (Irvine-Fynn et al., 2011). This is also true for the depth of surface snow, or of the firn-ice transition, which likewise vary spatially and temporally (Gusmeroli et al., 2012; Pälli et al., 2003). These boundaries are defined by compaction or density, controlled mainly by the porosity (Cuffey and Paterson, 2010), hence our discussion is also relevant for accurate measurement of these features. Higher porosities can result in water drainage (Murray et al., 2000a) resulting in an air-filled borehole. Energy signals from air-filled boreholes are more attenuated than from water-filled (Dubois, 1995), which should be considered in survey design, e.g. borehole separation.

We should also note that currently our quantification of error in water-content $\left(\phi_{w}\right)$ has not considered air-content $\left(\phi_{a}\right)$ errors, and has assumed the profile to be accurate and precise. Whilst realistically this is not true, we already demonstrated that small $(2 \%)$ errors in the $\phi_{a}$ have a tiny $(0.06 \%)$ influence on the calculation of $\phi_{w}$. We used an iterative approach, inferring $\phi_{w}$ from an input $\phi_{a}$, and assuming $\phi_{w}, \phi_{a} \geq 0$ is true at all depths; large deviation from the input air-content model suggests estimating $\phi_{a}$ from the pressure curve is unreliable, which is observed clearly for site A (Figure 6b). Overall faster velocities are measured at site A, with a velocity increase observed between 40 and $60 \mathrm{~m}$, approximately equal to the top of the temperate ice layer in Gusmeroli et al. (2012). Fountain et al. (2005) observed multiple fractures throughout the thickness of Storglaciären, extending to $96 \%$ of the depth; ice fractures cause strong electromagnetic anisotropy (Bradford et al., 2013) - if 
air-filled, this can result in an increased velocity. We interpret the faster velocities as an indication of underestimated macro-scale air-filled features.

The almost order-of-magnitude difference between $\varepsilon_{i}$ and $\varepsilon_{w}$ means (small) changes in bulk-ice radar velocity caused by air \% changes can be overwhelmed by bigger changes caused by water $\%$ change. Furthermore, because $\varepsilon_{i}$ is intermediate between $\varepsilon_{a}$ and $\varepsilon_{w}$, there will be [air+water] volume fractions whose bulk velocity appears to be that of ice. Hence, water and air content cannot both be quantified using radar data alone. To do so, an accurate determination of the air-content must be achieved, by some independent means, for both micro- AND macro-scale features. The influence of air appears more significant in the temperate ice layers and is influenced by stress directions, meaning air-content is likely to vary spatially. The smaller influence of air-content on the radar velocity means it does not require a highly accurate calculation to significantly improve the accuracy of the water-content whilst maintaining a high precision; this could be theoretically calculated from a co-located Vertical Seismic Profile (Gusmeroli et al., 2013).

\section{CONCLUSION}

We have evaluated the uncertainties in a cross-borehole radar survey undertaken in a glaciological setting. We found three main areas of uncertainty, resulting from picking the arrival times of data, instrument time drift, and borehole geometry - particularly where boreholes are drilled with hot water. We found that the largest error is caused by instrument drift, as the effect is random and extremely difficult to measure. We suggest methods to reduce each of these uncertainties through improvement of the existing data collection procedure.

Surface calibration data, collected prior to and after the survey to calculate time-zero 
correction and any instrument drift, should be acquired at multiple offsets, including one large offset. This allows a linear fit to be calculated through the measured travel times, improving the accuracy of the time-zero calculation, and preventing apparent instrument drift resulting from misplaced antennae. Data with a large time-drift should not be used for measuring small-scale velocity variations as the data are unreliable. For small $(20 \mathrm{~m})$ borehole separations, "large" drift can be as small as $\pm 1.5 \mathrm{~ns}$; although this increases for larger borehole separations; the total separation is limited by signal strength. Linear corrections can be applied to reduce the effect of drift. Data should be repeated, with measurements taken up- and down-borehole, in order to observe and hopefully remove any time jumps. When drilling with hot water, borehole width should be measured coincidently with inclination measurements. The borehole width will vary a minimum of $3 \mathrm{~cm}$ between the top and base of a $90 \mathrm{~m}$ borehole, and will not necessarily have a circular cross-section - depending on the heterogeneity of the ice melt, and englacial pressure.

We present cross-borehole data acquired in summer 2009, on Storglaciären, Arctic Sweden. We compared a minimal data collection procedure (site B) with a more detailed acquisition (site A), closer to our proposed revised survey techniques. We measure an improvement in the average velocity uncertainties from $3.0 \%( \pm 0.005 \mathrm{~m} / \mathrm{ns})$ for site $\mathrm{B}$, to $1.5 \%(0.003 \mathrm{~m} / \mathrm{ns})$ for site A. We also recalculate the uncertainties using the revised survey techniques, improving the model errors to $\pm 0.0013 \mathrm{~m} / \mathrm{ns}(0.8 \%)$ and $\pm 0.0015 \mathrm{~m} / \mathrm{ns}(0.9 \%)$, equivalent to a water-content precision of \pm 0.2 volumetric $\%$.

We demonstrate that our improved cross-borehole data acquisition has the ability to improve the water-content calculation so that determined values can be used for rheological analysis. However, it should be cautioned that these estimates are based on the assumption that the air-content is known. There is evidence of significant macro-scale air-content influ- 
ence on the radar velocity profiles at site A, which biases the water-content interpretation. It is necessary to calculate the air-content at each site, although not necessarily to the same precision as the water-content. The dominating influence of water-content on the radar velocity means that co-located techniques sensitive to density change must be used, e.g. a Vertical Seismic Profile.

\section{ACKNOWLEDGMENTS}

CA is funded by a NERC studentship (NE/J500367/1). The fieldwork was conducted by AG in 2009 and funded by a National Geographic grant. Special thanks to all the staff at Tarfala Research Station for their assistance during fieldwork. 


\section{REFERENCES}

Alumbaugh, D., P. Y. Chang, L. Paprocki, J. R. Brainard, R. J. Glass, and C. A. Rautman, 2002, Estimating moisture contents in the vadose zone using cross-borehole ground penetrating radar: A study of accuracy and repeatability: Water Resources Research, 38, $45-1$.

Annan, A., 2005, Investigations in Geophysics, No.13: Society of Exploration Geophysicists. (Edited by: D.K. Butler).

Arcone, S. A., 2002, Airborne-radar stratigraphy and electrical structure of temperate firn: Bagley Ice Field, Alaska, U.S.A.: Journal of Glaciology, 48, 317-334.

Barrett, B., T. Murray, and R. Clark, 2007, Errors in radar CMP velocity estimates due to survey geometry, and their implication for ice water content estimation: Journal of Environmental \& Engineering Geology, 12, 101-111.

Binley, A., G. Cassiani, R. Middleton, and P. Winship, 2002, Vadose zone flow model parameterisation using cross-borehole radar and resistivity imaging: Journal of Hydrology, 267, 147-159.

Bohleber, P., N. Wagner, and O. Eisen, 2012, Permittivity of ice at radio frequencies: Part II. Artificial and natural polycrystalline ice: Cold Regions Science and Technology, 83-84, $13-19$.

Bradford, J. H., J. Nichols, J. T. Harper, and T. Meierbachtol, 2013, Compressional and EM wave velocity anisotropy in a temperate glacier due to basal crevasses, and implications for water content estimation: Annals of Glaciology, 54, 168-178.

Bradford, J. H., J. Nichols, T. D. Mikesell, and J. T. Harper, 2009, Continuous profiles of electromagnetic wave velocity and water content in glaciers: an example from Bench Glacier, Alaska, USA: Annals of Glaciology, 50, 1-9. 
Cohen, D., 2000, Rheology of ice at the bed of Engabreen, Norway: Journal of Glaciology, 46, 611-621.

Cuffey, K. M., and W. S. B. Paterson, 2010, The physics of glaciers: Academic Press.

Dubois, J., 1995, Borehole radar experiment in limestone: analysis and data processing: First Break, 13.

Duval, P., 1977, The role of water content on the creep rate of polycrystalline ice: International Associations of Hydrological Sciences publication, 29-33.

Endres, A., and R. Knight, 1991, The effects of porescale fluid distribution on the physical properties of partially saturated tight sandstones: Journal of Applied Physics, 69, 10911098.

Endres, A., T. Murray, A. Booth, and L. West, 2009, A new framework for estimating englacial water content and pore geometry using combined radar and velocities: Geophysical Research Letters, 36, 1-5.

Fountain, A. G., R. W. Jacobel, R. Schlichting, and P. Jansson, 2005, Fractures as the main pathways of water flow in temperate glaciers: Nature, 433, 618-621.

Fujita, S., and S. Mae, 1993, Relation between ice sheet internal radio-echo reflections and ice fabric at Mizuho Station, Antarctica: Annals of Glaciology, 17, 269-275.

Fujita, S., T. Matsuoka, T. Ishida, K. Matsuoka, and S. Mae, 2000, A summary of the complex dielectric permittivity of ice in the megahertz range and its applications for radar sounding of polar ice sheets, first ed.: Hokkaido University Press. Physics of Ice Core Records.

Greaves, R., D. Lesmes, J. Lee, and M. Toksöz, 1996, Velocity variations and water content estimated from multi-offset, ground-penetrating radar: Geophysics, 61, 683-695.

Gusmeroli, A., 2010, Polythermal glacier dynamics at Storglaciären, Arctic Sweden, inferred 
using in situ geophysical techniques: PhD Thesis, Swansea University, UK.

Gusmeroli, A., P. Jansson, R. Pettersson, and T. Murray, 2012, Twenty years of cold surface layer thinning at Storglaciären, sub-Arctic Sweden, 1989-2009: Journal of Glaciology, 58, $3-10$.

Gusmeroli, A., T. Murray, R. Clark, B. Kulessa, and P. Jansson, 2013, Vertical seismic profiling of glaciers: appraising multi-phase mixing models: Annals of Glaciology, 54, 115.

Gusmeroli, A., T. Murray, P. Jansson, R. Pettersson, A. Aschwanden, and A. D. Booth, 2010, Vertical distribution of water within the polythermal Storglaciären, Sweden: Journal of Geophysical Research, 115.

Heidary, A., 2010, A low-cost universal integrated interface for capacitive sensors: TU Delft, Delft University of Technology.

Heilig, A., M. Schneebeli, and O. Eisen, 2009, Upward-looking ground-penetrating radar for monitoring snowpack stratigraphy: Cold Regions Science and Technology, 59, 152-162.

Heucke, E., 1999, A Light Portable Steam-Driven Ice Drill Suitable for Drilling Holes in Ice and Firn: Geografiska Annaler. Series A, Physical Geography, 81, 603-609.

Holmlund, P., P. Jansson, and R. Pettersson, 2005, A re-analysis of the 58 year mass balance record of Storglaciären, Sweden: Annals of Glaciology, 42, 389-394.

Hubbard, B., and P. Nienow, 1997, Alpine subglacial hydrology: Quaternary Science Reviews, 16, 939-955.

Huisman, J. A., S. S. Hubbard, J. D. Redman, and A. P. Annan, 2003, Measuring Soil Water Content with Ground Penetrating Radar: A Review: Vadose Zone Journal, 2, $476-491$.

Hutter, K., A. Zryd, and M. Röthlisberger, 1990, On the numerical solution of stefan 
problems in temperate ice: Journal of Glaciology, 36, 41-48.

Ingvander, S., G. Rosqvist, J. Svensson, and H. E. Dahlke, 2013, Seasonal and interannual variability of elemental carbon in the snowpack of Storglaciären, northern Sweden: Annals of Glaciology, 54, 50-58.

Irvine-Fynn, T., A. Hodson, B. Moorman, G. Vatne, and A. Hubbard, 2011, Polythermal glacier hydrology: a review: Reviews of Geophysics, 49, RG4002.

Jansson, P., 1996, Dynamics and hydrology of a small polythermal valley glacier: Geografiska Annaler. Series A, Physical Geography, 78, 171-180.

Jansson, P., and J.-O. Näslund, 2009, Spatial and temporal variations in glacier hydrology on Storglaciaren, Sweden. Technical Report: TR-09-13: Technical Report June, Stockholm University, Physical Geography and Quaternary Geology.

Johari, G., and P. Charette, 1975, The permittivity and attenuation in polycrystalline and single-crystal ice Ih at 35 and $60 \mathrm{MHz}$ : Journal of Glaciology, 14, 293-303.

Kaatze, U., 2007, Reference liquids for the calibration of dielectric sensors and measurement instruments: Measurement Science and Technology, 18, 967-976.

Lliboutry, L., 1976, Physical processes in temperate glaciers: Journal of Glaciology, 16, $151-158$.

Looyenga, H., 1965, Dielectric constants of heterogeneous mixture: Molecular Physics, 31, $501-511$.

Lüthi, M., M. Funk, A. Iken, S. Gogineni, and M. Truffer, 2002, Mechanisms for fast flow in Jakobshaven Isbræ, West Greenland: Part III. Measurements of ice deformation, temperature and cross-borehole conductivity in boreholes to the bedrock: Journal of Glaciology, 48, 369-385.

Macheret, Y., and A. Glazovsky, 2000, Estimation of absolute water content in Spitsbergen 
glaciers from radar sounding data: Polar Research, 19, 205-216.

Mader, H., 1992, Observations of the water-vein system in polycrystalline ice: Journal of Glaciology, 38, 333-347.

Mätzler, C., and U. Wegmüller, 1987, Dielectric properties of fresh-water ice at microwave frequencies: Journal of Physics D: Applied Physics, 20, 1623-1630.

Mavko, G., T. Mukerji, and J. Dvorkin, 2009, The rock physics handbook: Tools for seismic analysis of porous media: Cambridge university press.

Moore, J. C., A. Pälli, F. Ludwig, and H. Blatter, 1999, High-resolution hydrothermal structure of Hansbreen, Spitsbergen, mapped by ground-penetrating radar: Journal of Glaciology, 45, 524-532.

Murray, T., A. Booth, and D. M. Rippin, 2007, Water-content of glacier-ice: limitations on estimates from velocity analysis of surface ground-penetrating radar surveys: Journal of Environmental \& Engineering Geophysics, 12, 87-99.

Murray, T., G. Stuart, M. Fry, N. Gamble, and M. D. Crabtree, 2000a, Englacial water distribution in a temperate glacier from surface and borehole radar velocity analysis: Journal of Glaciology, 46, 389-398.

Murray, T., G. Stuart, P. Miller, J. Woodward, A. Smith, P. Porter, and H. Jiskoot, 2000b, Glacier surge propagation by thermal evolution at the bed: Journal of Geophysical Research, 105, 13491-13507.

Oberröhrmann, M., A. Klotzsche, H. Vereecken, and J. van der Kruk, 2013, Optimization of acquisition setup for cross-hole gpr full-waveform inversion using checkerboard analysis: Near Surface Geophysics, 11, 197-209.

Pälli, A., J. C. Moore, and C. Rolstad, 2003, Firn-ice transition-zone features of four polythermal glaciers in svalbard seen by ground-penetrating radar: Annals of glaciology, 37, 
$298-304$.

Peterson, Jr, J. E., 2001, Pre-inversion Corrections and Analysis of Radar Tomographic Data: Journal of Environmental \& Engineering Geophysics, 6, no. 1, 1-18.

Pettersson, R., P. Jansson, and H. Blatter, 2004, Spatial variability in water content at the cold-temperate transition surface of the polythermal Storglaciären, Sweden: Journal of Geophysical Research, 109.

Schoenberger, M., 1974, Resolution comparison of minimum-phase and zero-phase signals: Geophysics, 39, 826-833.

Schoof, C., 2012, Thermally driven migration of ice-stream shear margins: Journal of Fluid Mechanics, 712, 552-578.

Schwerzmann, A., M. Funk, and H. Blatter, 2006, Instruments and methods. borehole logging with an eight-arm caliper-inclinometer probe: Journal of Glaciology, 52, 381388.

Sensors \& Software Inc. 2006, pulseekko pro users guide. 1040 Stacey Court, Mississauga, ON L4W 2X8, Canada. (Sections 17.8 and 19.6).

Topping, J., and F. Worrell, 1957, Errors of observation and their treatment: American Journal of Physics, 25, 498.

Tronicke, J., and M. D. Knoll, 2005, Vertical radar profiling: influence of survey geometry on first-arrival traveltimes and amplitudes: Journal of Applied Geophysics, 57, 179-191.

Turner, G., and A. F. Siggins, 1994, Constant Q attenuation of subsurface radar pulses: Geophysics, 59, 1192-1200.

Vallon, M., J. Petit, and B.Fabre, 1976, Study of an ice core to the bedrock in the accumulation zone of an alpine glacier: Journal of Glaciology, 17, 13-28.

Walford, M. E. R., M. I. Kennett, and P. Holmlund, 1987, INTERPRETATION OF RADIO 
ECHOES FROM STORGLACIÄREN, NORTHERN SWEDEN: Journal of Glaciology, 33, 39-49.

York, D., N. M. Evensen, M. L. Martínez, and J. D. B. Delgado, 2004, Unified equations for the slope, intercept, and standard errors of the best straight line: American Journal of Physics, 72, 367.

Zryd, A., 1991, Conditions dans la couche basale des glaciers tempéreés: contraintes, teneur en eau et frottement intérieur: PhD Thesis, ETH Institute of Geography, Zürich, Switzerland. ([Online; accessed 20/02/2012]). 


\section{LIST OF TABLES}

1 Key survey site information for each field season on Storglaciären. The average calculated instrument drift for each site is shown \pm 1 standard deviation $(\tilde{\sigma})$ - a large $\tilde{\sigma}$ indicates a large range in values - and average velocity $\left(\bar{v}_{m}\right)$ with percentage uncertainty $\left(d \bar{v}_{m}\right)$, and the fractional water-content $\left(\phi_{w}\right)$, for each survey site, including $1 \tilde{\sigma}$. 


\section{LIST OF FIGURES}

1 (a) Cross-borehole survey: receiver and transmitter at equal depth in centre of two adjacent boreholes (surface separation $=\mathrm{S}$ ). Each antenna moves a distance $(\mathrm{dz})$ between measurements in down- (surface-to-base) or up-hole directions. Energy arrival indicated by sudden increase in amplitude (from 0) on the data record (right, highlighted). (b) Vertical cross-section: antenna in inclined borehole. Antennae angle $(\beta)$ depends on the borehole $\operatorname{dip}(\gamma)$, antenna length $\left(A_{l}\right)$ and diameter $\left(A_{W}\right)$, and the borehole diameter $\left(D_{W}\right)$.

2 (a) A simple model of uncertainties in cross-borehole surveys. (b) The effect of uncertainties changing the energy relative to the predicted wavelet, and shifting the firstbreak $\left(t_{a}\right)$. (1) Data recorded by near-surface antennae can interfere with and obscure the first-break. (2) Underestimated borehole diameter results in a smaller $t_{a}$ from less travel time spent in the slow velocity water; assuming a constant borehole diameter results in an overestimated ice velocity. (3) Inclined boreholes result in an angled antenna, and inclined raypath (vertical depth $\neq$ borehole depth); this also decreases $t_{a}$. The predicted wavelet is shown as a dotted line in (1), (2) and (3).

3 Ablation area map of Storglaciären (SG), Arctic Sweden, marking the locations of boreholes drilled for each cross-borehole survey site. The surface contours and approximate crevasse locations (Jansson and Näslund, 2009) are marked over the glacier for reference. The data were collected during the summer period, with the survey year marked in the key. The coordinate system is in RT90, with lateral distances measured in metres. The left inset photograph of the glacier marks the area of enlarged map (dashed box). The right inset shows the location of SG in Sweden.

4 (a) An example of a survey at site A. (1) Surface data are collected before and after the main data, at two offsets: $5 \mathrm{~m}$, and the borehole separation (S). (2) The main 
borehole data are collected between 1 and $64 \mathrm{~m}$ depth, in down- and up-hole directions. (b) The antenna separation for the entire survey. This has a strong influence on the pattern in the main borehole data.

$5 \quad$ Average velocity models for both Storglaciären field sites; cold ice velocity $\left(v_{i}=0.168\right.$ $\mathrm{m} / \mathrm{ns}$ ) marked for comparison. Site A surface velocities close to $0.168 \mathrm{~m} / \mathrm{ns}$, followed by velocity increase to $\sim 60 \mathrm{~m}$, then a velocity decrease to depth $(112 \mathrm{~m})$. Site B shows a twolayer structure, with a sharp velocity decrease at $21 \mathrm{~m}$ and generally larger uncertainties. Shaded regions indicate the velocity uncertainties at each depth in the model.

6 (a) Average Water-Content $\left(\phi_{w}\right)$ Models for each site, calculated from average velocity profiles; uncertainties are shown by the shaded regions. Site A indicates $\phi_{w} \approx 0 \%$ for all depths. Site B shows a sharp increase in $\phi_{w}$ at $21 \mathrm{~m}$ depth from $0.25 \%$ to $0.6 \%$. Average $\phi_{w}$ at each site: $\mathrm{A}=0.06 \pm 0.35 \%$, and $\mathrm{B}=0.51 \pm 0.79 \%$. (b) Air-content $\left(\phi_{a}\right)$ profiles used to calculate the $\phi_{w}$ in (a), estimated from an input pressure curve (grey line; Bradford et al., 2009), decreasing from the surface; deviation from the input $\phi_{a}$ indicates an incorrect model. The calculation is adapted to assume $\phi_{w}, \phi_{a}<0$ is not true. Error in $\phi_{a}$ are not included in the $\phi_{w}$ uncertainties. 

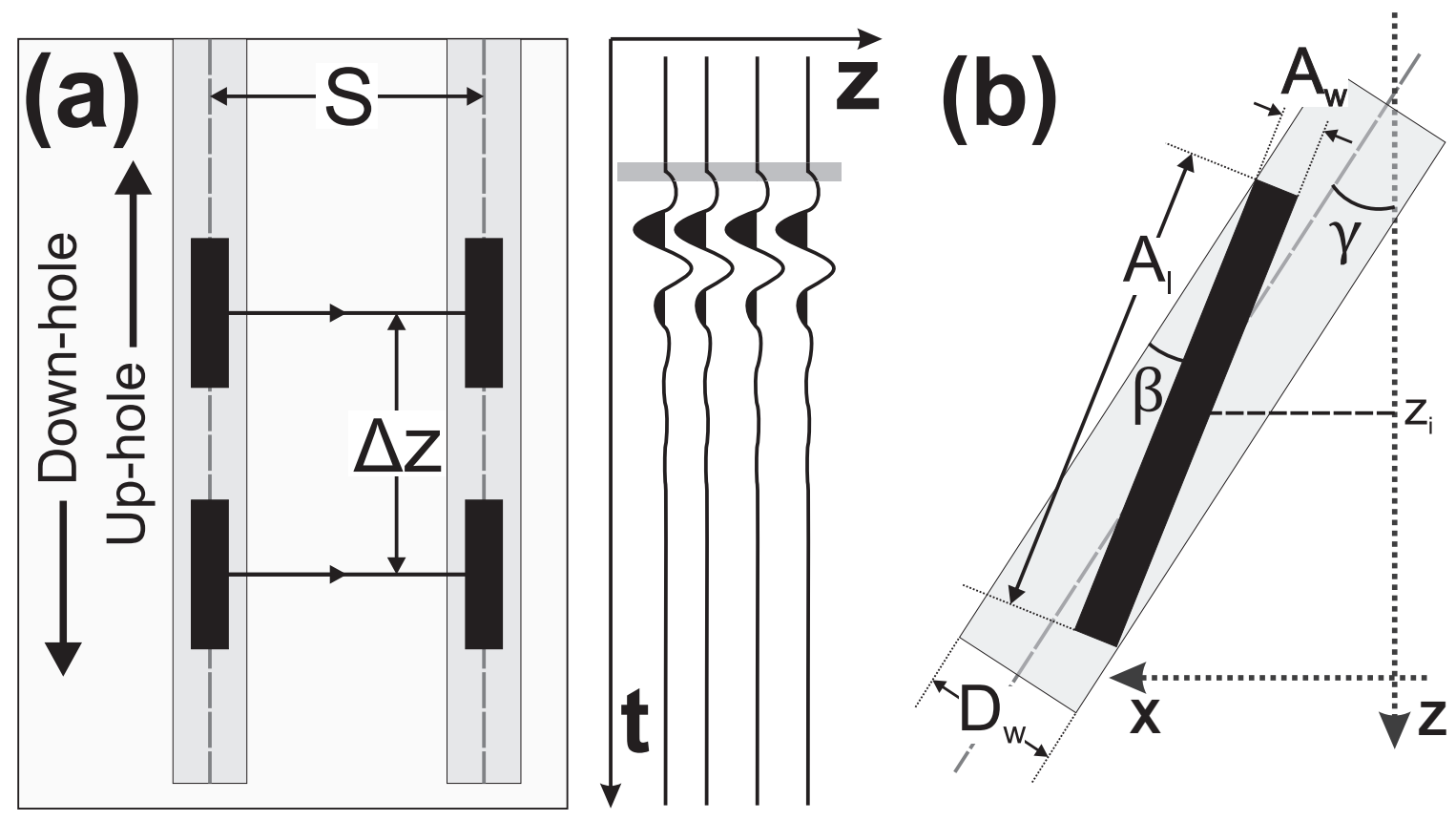

Figure 1: (a) Cross-borehole survey: receiver and transmitter at equal depth in centre of two adjacent boreholes (surface separation $=\mathrm{S})$. Each antenna moves a distance $(\mathrm{dz})$ between measurements in down- (surface-to-base) or up-hole directions. Energy arrival indicated by sudden increase in amplitude (from 0) on the data record (right, highlighted). (b) Vertical cross-section: antenna in inclined borehole. Antennae angle $(\beta)$ depends on the borehole dip $(\gamma)$, antenna length $\left(A_{l}\right)$ and diameter $\left(A_{W}\right)$, and the borehole diameter $\left(D_{W}\right)$.

Axtell et al. - Second Revision 

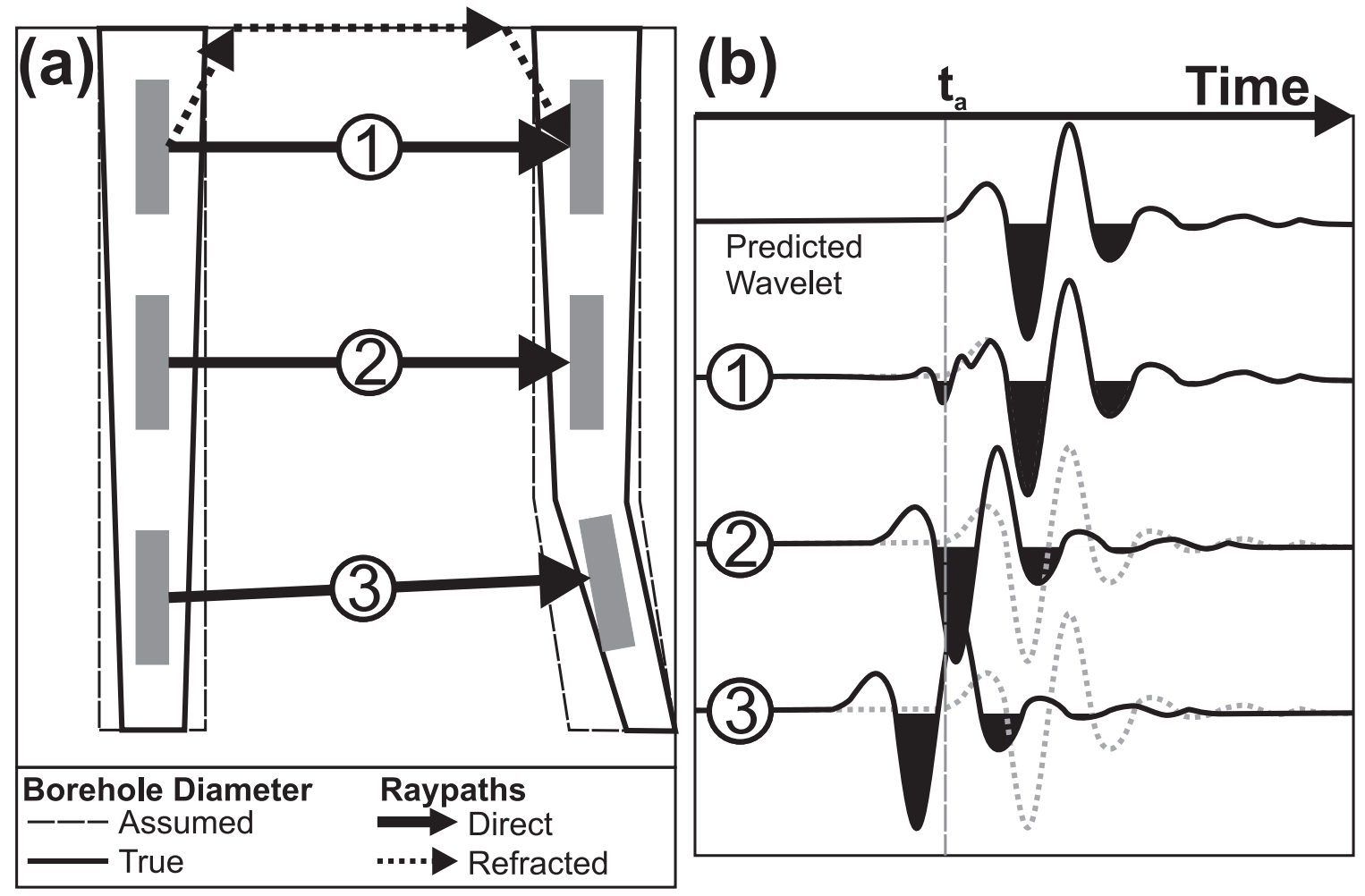

Figure 2: (a) A simple model of uncertainties in cross-borehole surveys. (b) The effect of uncertainties changing the energy relative to the predicted wavelet, and shifting the first-break $\left(t_{a}\right)$. (1) Data recorded by near-surface antennae can interfere with and obscure the first-break. (2) Underestimated borehole diameter results in a smaller $t_{a}$ from less travel time spent in the slow velocity water; assuming a constant borehole diameter results in an overestimated ice velocity. (3) Inclined boreholes result in an angled antenna, and inclined raypath (vertical depth $\neq$ borehole depth); this also decreases $t_{a}$. The predicted wavelet is shown as a dotted line in (1), (2) and (3).

Axtell et al. - Second Revision 


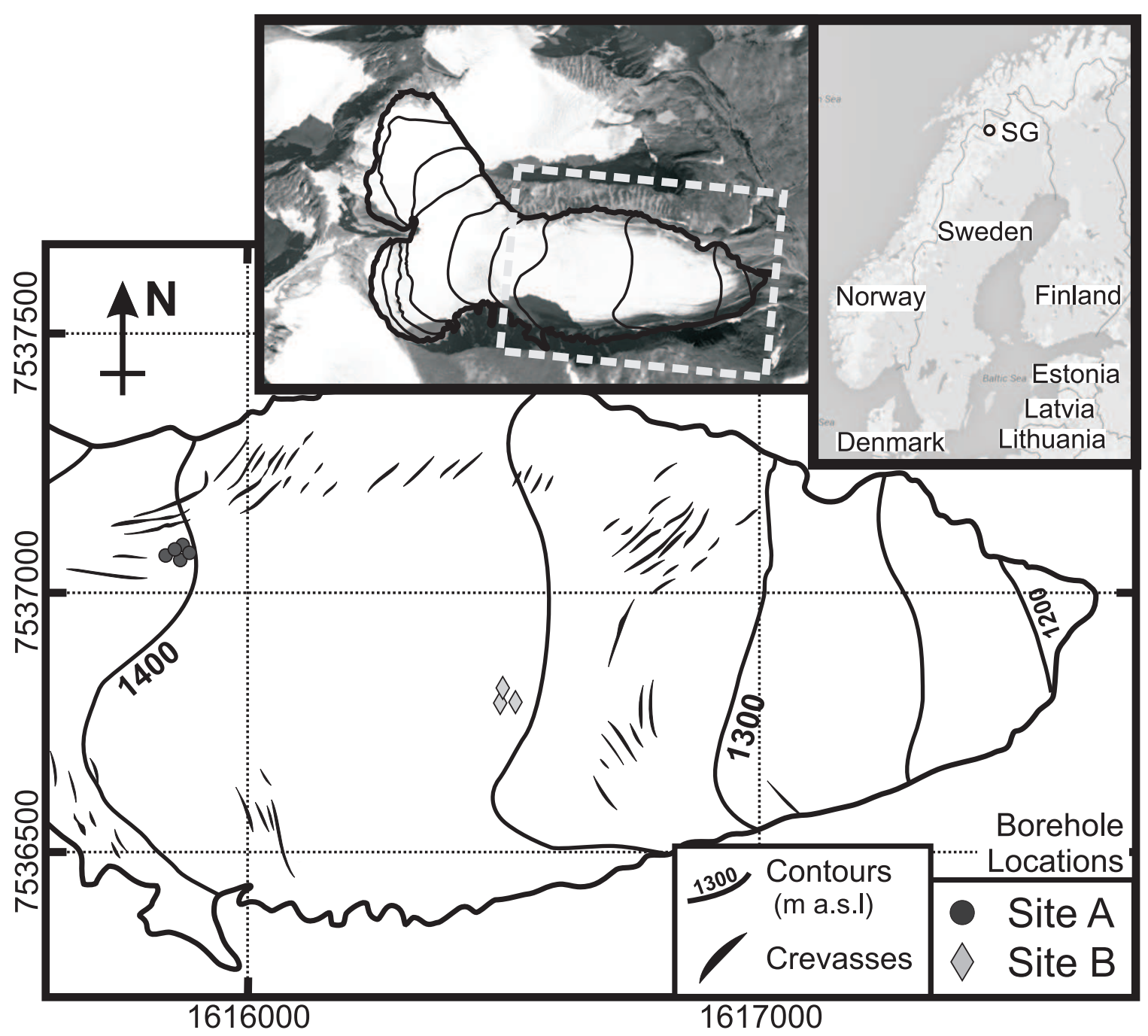

Figure 3: Ablation area map of Storglaciären (SG), Arctic Sweden, marking the locations of boreholes drilled for each cross-borehole survey site. The surface contours and approximate crevasse locations (Jansson and Näslund, 2009) are marked over the glacier for reference. The data were collected during the summer period, with the survey year marked in the key. The coordinate system is in RT90, with lateral distances measured in metres. The left inset photograph of the glacier marks the area of enlarged map (dashed box). The right inset shows the location of SG in Sweden.

Axtell et al. - Second Revision 


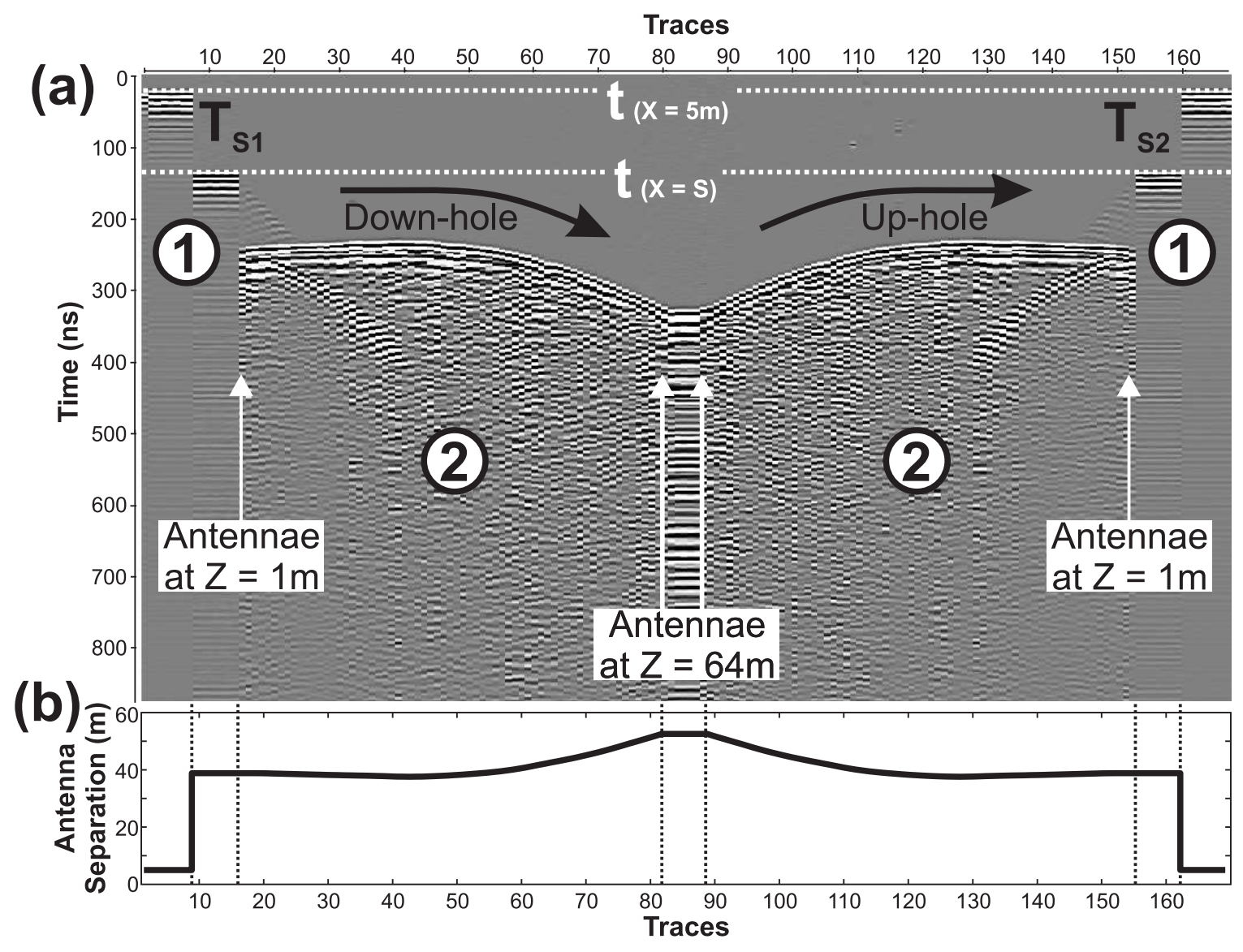

Figure 4: (a) An example of a survey at site A. (1) Surface data are collected before and after the main data, at two offsets: 5m, and the borehole separation (S). (2) The main borehole data are collected between 1 and $64 \mathrm{~m}$ depth, in down- and up-hole directions. (b) The antenna separation for the entire survey. This has a strong influence on the pattern in the main borehole data.

Axtell et al. - Second Revision 


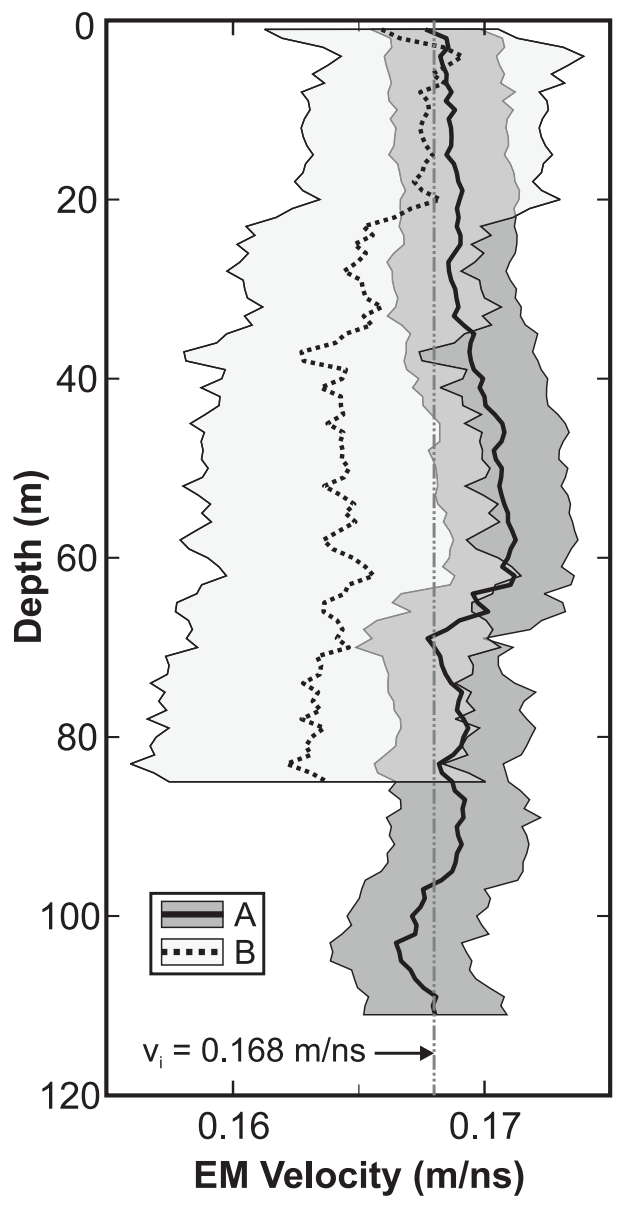

Figure 5: Average velocity models for both Storglaciären field sites; cold ice velocity $\left(v_{i}=0.168\right.$ $\mathrm{m} / \mathrm{ns}$ ) marked for comparison. Site A surface velocities close to $0.168 \mathrm{~m} / \mathrm{ns}$, followed by velocity increase to $\sim 60 \mathrm{~m}$, then a velocity decrease to depth $(112 \mathrm{~m})$. Site B shows a two-layer structure, with a sharp velocity decrease at $21 \mathrm{~m}$ and generally larger uncertainties. Shaded regions indicate the velocity uncertainties at each depth in the model.

Axtell et al. - Second Revision 


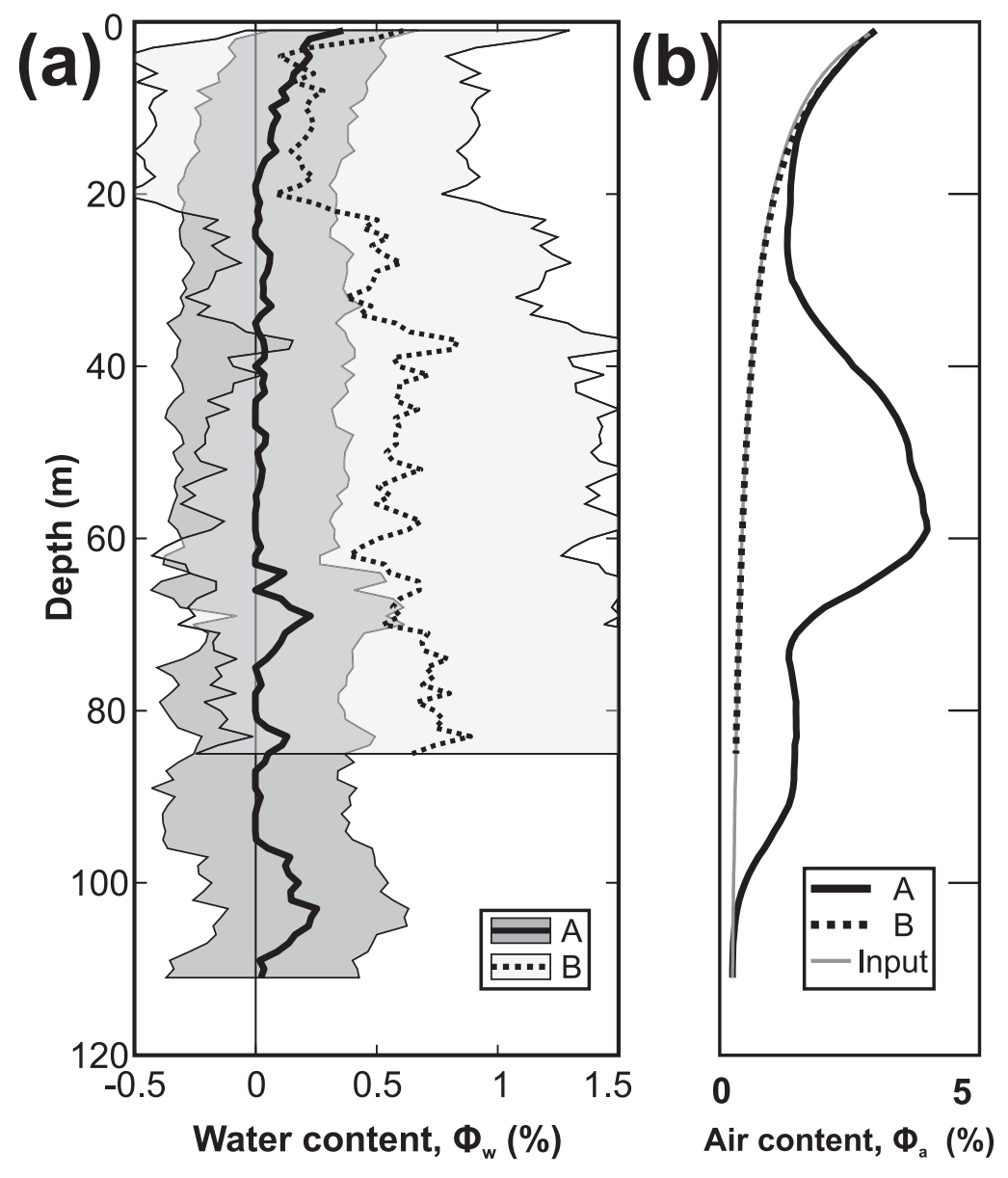

Figure 6: (a) Average Water-Content $\left(\phi_{w}\right)$ Models for each site, calculated from average velocity profiles; uncertainties are shown by the shaded regions. Site A indicates $\phi_{w} \approx 0 \%$ for all depths. Site B shows a sharp increase in $\phi_{w}$ at $21 \mathrm{~m}$ depth from $0.25 \%$ to $0.6 \%$. Average $\phi_{w}$ at each site: $\mathrm{A}=0.06 \pm 0.35 \%$, and $\mathrm{B}=0.51 \pm 0.79 \%$. (b) Air-content $\left(\phi_{a}\right)$ profiles used to calculate the $\phi_{w}$ in (a), estimated from an input pressure curve (grey line; Bradford et al., 2009), decreasing from the surface; deviation from the input $\phi_{a}$ indicates an incorrect model. The calculation is adapted to assume $\phi_{w}, \phi_{a}<0$ is not true. Error in $\phi_{a}$ are not included in the $\phi_{w}$ uncertainties.

Axtell et al. - Second Revision 


\begin{tabular}{|c|c|c|c|}
\hline Site & Drift & $\overline{\boldsymbol{v}}_{\boldsymbol{m}} \pm \tilde{\boldsymbol{\sigma}}(\mathbf{m} / \mathbf{n s})$ & $\boldsymbol{\phi}_{\boldsymbol{w}} \pm \tilde{\boldsymbol{\sigma}}(\mathbf{\%})$ \\
& $\pm \tilde{\boldsymbol{\sigma}}(\mathbf{n s})$ & $\left( \pm \boldsymbol{d} \overline{\boldsymbol{v}}_{\boldsymbol{m}}\right)$ & $\left( \pm d \phi_{w}\right)$ \\
\hline $\mathbf{A}$ & $1.0 \pm 0.8$ & $0.169 \pm 0.001$ & $0.06 \pm 0.07$ \\
& & $( \pm 0.0024)$ & $( \pm 0.41 \%)$ \\
\hline B & $0.9 \pm 0.6$ & $0.165 \pm 0.002$ & $0.51 \pm 0.20$ \\
& & $( \pm 0.0043)$ & $( \pm 1.31 \%)$ \\
\hline
\end{tabular}

Table 1: Key survey site information for each field season on Storglaciären. The average calculated instrument drift for each site is shown \pm 1 standard deviation $(\tilde{\sigma})$ - a large $\tilde{\sigma}$ indicates a large range in values - and average velocity $\left(\bar{v}_{m}\right)$ with percentage uncertainty $\left(d \bar{v}_{m}\right)$, and the fractional water-content $\left(\phi_{w}\right)$, for each survey site, including $1 \tilde{\sigma}$. 